\title{
Ethnopharmacological activity of Hedera nepalensis K. Koch extracts and lupeol against alloxan-induced type I diabetes
}

\author{
Waleed Javed Hashmi' ${ }^{1}$ Hammad Ismail ${ }^{2}$, Laila Jafri ${ }^{1}$, Bushra Mirza ${ }^{\circledR *}$ \\ ${ }^{1}$ Department of Biochemistry, Faculty of Biological Sciences, Quaid-i-Azam University, \\ Islamabad, Pakistan, Department of Life Sciences, Abasyn University Islamabad \\ Campus, Islamabad, Lahore College for Women University, Lahore ${ }^{2}$ Department \\ of Biochemistry and Biotechnology, University of Gujrat, Gujrat, Pakistan
}

\begin{abstract}
In this study, we investigated the protective effects of Hedera nepalensis crude extract, its fractions and lupeol in alloxan-induced diabetic rats. Lupeol and n-hexane (HNN) fraction significantly reduced the blood glucose level by increasing insulin level in time dependent manner, and also significantly increased amylase and lipase activity in diabetic rats. Elevated levels of alanine transaminases (ALT), aspartate transaminases (AST), thiobarbituric acid reactive substances (TBARS), nitrite, hydrogen peroxide $\left(\mathrm{H}_{2} \mathrm{O}_{2}\right)$, total bilirubin and total protein in blood serum were efficiently restored to normal levels. Suppressed enzymatic activity of catalase (CAT), superoxide dismutase (SOD), reduced glutathione (GSH) and peroxidase (POD) were also restored to their normal levels. Kidney functions were also restored to normal level after treatment with $\mathrm{HNN}$ and lupeol. HNN fraction and lupeol of H. nepalensis prevented oxidative stress in alloxan-induced diabetic rats. This study signifies the importance of $H$. nepalensis and lupeol in ameliorating diabetes by inducing insulin secretion in diabetic model rats.
\end{abstract}

Keywords: Antioxidant. Amylase. Diabetes mellitus. Insulin. Hedera nepalensis. Lupeol.

\section{INTRODUCTION}

Diabetes Mellitus (DM) is a metabolic disorder characterized by high blood glucose concentration (hyperglycaemia) due to insufficient secretion of insulin from pancreatic $\beta$-cells (Jarald, Joshi, Jain, 2008). Glycogen breakdown exacerbates due to low insulin secretion, leading to low hepatic glycogen level. Abnormal glycogen metabolism causes overexpression of the liver marker enzymes: transaminases and phosphatases (Amarapurkar, Das, 2001). Diabetes causes oxidative stress that acts to change cellular physiology, with decreased level of catalase (CAT), renal superoxide dismutase (SOD) and reduced glutathione (GSH) (Tiwari

*Correspondence: B. Mirza, Department of Biochemistry, Faculty of Biological Sciences, Quaid-i-Azam University, Islamabad, Pakistan. Telephone:+92-51-90643007, Fax:+92-51-90644050.Email: bushramirza@ qau.edu.pk. These authors contributed equally in work. et al., 2013). Oxidative stress has been implicated as major factor leading to pathogenesis and complication of diabetes (Nakhjavani et al., 2013). Liver is the most affected organ in chronic diabetes (Leclercq et al., 2007). Globally, about 170 million people are diabetic, and it is estimated that this figure will double by 2030 (Marx, 2002). Development of new therapies to ameliorate DM is a hot research area.

Since beginning of human civilization, plants extracts have been used to treat various ailments. To date, about $50 \%$ of all medicines in clinical trial for evaluation are extracted from natural product (derivatives or analogs), and plants contribute more than $25 \%$ of all therapeutic agents (Gurib-Fakim, 2006). Secondary metabolites of plants are preferred over synthetic compounds as drugs, because they are more biological friendly and effective within living system. In Asia and Africa, herbs proven to be medicinally important for diabetes have been used for centuries. Inspite of little 
scientific evidence for use of plant based medicine, traditional plant drugs have been used because of their minimal side effects and low cost (Ismail, Mirza, 2015).

Genus Hedera (family Araliaceae) is distributed in North Europe, Asia, China, Japan and North Africa. Many species of genus Hedera are present in Northern areas of Pakistan. Hedera nepalensis is among one of the most valuable plants to treat different diseases. It has spasmolytic, sedative, antihelmintic, molluscicidal, antileishmanial and antifungal properties (Xue, ZhiYing, 2010). Catechin and caffeic acid have been reported in ethyl acetate fraction of $H$. nepalensis, along with phenolic compounds that have promising antioxidant activity (Jafri et al., 2014). The plant is also effective against tumour cells (Hamayun et al., 2006). In vitro biological activities, including brine shrimp cytotoxicity, potato disc antitumor activity and phytotoxic activity exhibited promising results (Inayatullah et al., 2007). The phytochemical analysis of $H$. nepalensis showed the presence of alkaloids, flavonoids, steroids, tannins and terpenoids (Kanwal et al., 2011).

$H$. nepalensis has been reported in literature as a natural folk medicine, particularly for the treatment of diabetes (Ríos, Francini, Schinella, 2015) in the subcontinent. Akhtar et al. (2013) reported that juice from leaves of $H$. nepalensis is used to cure diabetes and to purify blood. Dried branches and leaves of $H$. nepalensis are grinded and the powder is used early in the morning with water against diabetes in the temperate Himalayan region (Begum et al. 2014). Here we evaluate the hypoglycaemic and in vivo antioxidant activity of $H$. nepalensis crude extract (HNC) and fractions (HNN, HNE and HNA), along with one purified compound lupeol.

\section{MATERIAL AND METHODS}

\section{Plant collection}

The plant $H$. nepalensis under the local name of Bumbar was collected in September 2016 from Nathia Gali (District Rawalpindi, Punjab, Pakistan). The Plant was taxonomically identified by Dr. Rizwana Aleem Qureshi, Department of Plant Science, Faculty of Biological Sciences, Quaid-i-Azam University, Islamabad. Plant specimen was deposited under the voucher specimen HMP-461 in the "Herbarium of medicinal plants of Pakistan", Quaid-i-Azam University, Islamabad, Pakistan.

\section{Preparation of plant extract and isolation of lupeol}

Plant material was dried under shade, ground into fine powder and then macerated in methanol and chloroform mixture (1:1). The eluted solution was concentrated in rotary evaporator (Buchi, Switzerland) to get $H$. nepalensis crude extract (HNC). The suspension of HNC obtained after mixing in hot distilled water, was subjected to partition three times with n-hexane. HNN (n-hexane) fraction obtained after concentrating with rotary evaporator yielded residual aqueous portion that was used to partition three times with ethyl acetate solution followed by rotary evaporation to get HNE fraction. Similarly, residual aqueous layer produced HNA fraction after concentrating in rotary evaporator. These extracts were stored at $-20{ }^{\circ} \mathrm{C}$ for further studies. Lupeol was isolated previously by our research group (Saleem et al., 2014) as a white powder from the HNN fraction and has the molecular formula of $\mathrm{C}_{30} \mathrm{H}_{50} \mathrm{O}(\mathrm{m} / \mathrm{z} 426.72)$ as suggested by mass spectral data. Lupeol solution was prepared as $5 \mathrm{mg} / \mathrm{kg} \mathrm{BW}$ dissolved in $10 \%$ DMSO for experiments.

\section{Animal maintenance}

Male Sprague-Dawley rats weighing 200-250 g were chosen for in-vivo assays. They were kept in aluminium cages maintained in ventilated room with free access to food and tap water. The study protocols were approved by Ethical Committee of Quaid-i-Azam University, Islamabad. All experiments were conducted in accordance with the National Biosafety Guideline.

\section{Maximum dose tolerance test}

For chemical testing, the acute toxicity studies were performed as per the guidelines 425 of Organization for Economic Cooperation and Development (OECD) (OECD, 2001). For this purpose, the rats were subjected to various doses of the extracts $(125,250,500,750$ and $1000 \mathrm{mg} / \mathrm{kg} \mathrm{BW}$ ) orally along with saline solution $(10 \mathrm{~mL} / \mathrm{kg})$ as control. Any mortality, toxicity and behavioural changes were monitored for one week after oral administration.

\section{Induction of diabetes}

Diabetes was induced in rats by a single intraperitoneal injection $(0.2 \mathrm{~mL})$ of $120 \mathrm{mg} / \mathrm{kg}$ of alloxan monohydrate dissolved in DMSO. After 48 
hours, blood was taken from tail of the rats kept on fasting for 9 hours (only 10\% glucose solution diet). Glucose level was determined to confirm the induction of diabetes using test strips in Lifescan one touch Vita ${ }^{\mathrm{TM}}$ test meter. Diabetic rats with glucose level $>300 \mathrm{mg} / \mathrm{dL}$ were used for further experiments.

\section{Treatment groups and antidiabetic study}

Total fifty-six Sprague-Dawley male rats were randomly distributed into eight groups, each group containing seven rats. Group-I (NC, normal control, non-diabetic) received $10 \%$ DMSO administered orally (10 mL/kg BW/day). Group-II (DC, diabetic control) received $10 \%$ DMSOperdayorally. Group-III $(\mathrm{DC}+\mathrm{HNC})$ received crude extract. Group-IV $(\mathrm{DC}+\mathrm{HNN})$ received n-hexane fraction. Group-V (DC+HNE) received ethyl acetate fraction. Group-VI (DC+HNA) received aqueous fraction. Group VII (DC+lupeol) received lupeol orally at $5 \mathrm{mg} / \mathrm{kg} \mathrm{BW} /$ day dissolved in $10 \%$ DMSO. Group VIII (DC + glibenclamide) received glibenclamide orally at $5 \mathrm{mg} / \mathrm{kg} \mathrm{BW/day}$ as standard drug dissolved in $10 \%$ DMSO. All the experimental groups were fed orally at $400 \mathrm{mg} / \mathrm{kg} \mathrm{BW} /$ day of extract dissolved in $10 \%$ DMSO. The treatments were carried out for 14 consecutive days. Glucose level was determined on day 0 at $0 \mathrm{~h}, 0.5 \mathrm{~h}, 1 \mathrm{~h}$, $2 \mathrm{~h}$ and $4 \mathrm{~h}$ and day 3, 6, 9, 12, 15 from rats blood taken from tail vein using test strips in Lifescan one touch $\mathrm{Vita}^{\mathrm{TM}}$ test meter.

\section{Serum and tissue preparation}

On day 15, after glucose determination, the rats were anesthetized with chloroform and sacrificed to get blood by cardiac puncture. The blood was collected in BD Vacutainer ${ }^{\circledR}$ tubes and then centrifuged at 3500 rpm for $10 \mathrm{~min}$ to separate the serum. Kidney, heart, liver and pancreas were separated from the rats, washed thoroughly with saline and stored at $-20^{\circ} \mathrm{C}$ for future use.

\section{Determination of biochemical markers of pancreas, liver, kidney and heart}

Pancreatic enzymes such as amylase and lipase were estimated in the serum of treated animals according to the guidelines mentioned on supplier's standard kits levels using the Cobas ${ }^{\circledR}$ kits (Roche Diagnostics, Indianapolis, IN, USA). Quantitative estimation of insulin in rat serum was accomplished with the help of an enzyme-linked immunosorbent assay (ELISA) using a commercial kit (Micro LISA Insulin Amgenix, USA) according to the protocol provided in the kit. Biochemical markers such as ALT, AST, total bilirubin, total protein, creatinine and BUN were estimated in the serum acquired from the treated animals according to the guidelines mentioned on supplier's standard kits levels using the Cobas ${ }^{\circledR}$ kits (Roche Diagnostics, Indianapolis, IN, USA).

\section{Determination of antioxidant markers}

Tissue parts (100 mg) of heart, kidney, liver and pancreas of every animal were homogenized in ice cold $50 \mathrm{mM}$ tris buffer $(\mathrm{pH} 7.4)$ and centrifuged at 10,000 rpm for $30 \mathrm{~min}$ at $4{ }^{\circ} \mathrm{C}$. The supernatant was analysed for CAT, SOD, protein estimation, POD, TBARS, GSH, nitrite and hydrogen peroxide as detailed below:

\section{CAT activity}

CAT activity was measured following Aebi (1984) with slight modifications. The reaction mixture comprised of $2.5 \mathrm{~mL}$ of $50 \mathrm{mM}$ phosphate buffer ( $\mathrm{pH} 5.0$ ), $0.4 \mathrm{~mL}$ of $5.9 \mathrm{mM} \mathrm{H}_{2} \mathrm{O}_{2}$ and $0.1 \mathrm{~mL}$ tissue homogenate. After $1 \mathrm{~min}$, absorbance was calculated at $240 \mathrm{~nm}$ using microtitre plate reader and results were represented as $\mathrm{U} / \mathrm{min}$. Total protein was measured using the Bradford method at $650 \mathrm{~nm}$.

\section{SOD activity}

SOD activity was analysed by the method of Bannister and Calabrese (2006). Reaction mixture contained $0.1 \mathrm{~mL}$ of phenazine methosulphate $(186 \mu \mathrm{M})$, $1.2 \mathrm{~mL}$ of phosphate buffer $(\mathrm{pH} 7.0)$ and $0.3 \mathrm{~mL}$ of tissue sample followed by the addition of $0.2 \mathrm{~mL}$ of NADH $(780 \mu \mathrm{M})$. After $1 \mathrm{~min}, 1 \mathrm{~mL}$ of glacial acetic acid was added to stop reaction and absorbance was measured at $560 \mathrm{~nm}$. The SOD activity is expressed as U/mg protein.

\section{POD activity}

POD activity was measured following Khan et al. (2015), with some modification. The reaction mixture contained $625 \mu \mathrm{L}$ of $50 \mathrm{mM}$ phosphate buffer ( $\mathrm{pH} 5.0$ ), $25 \mu \mathrm{L}$ of $20 \mathrm{mM}$ guaiacol, $25 \mu \mathrm{L}$ of tissue sample and $75 \mu \mathrm{L}$ of $40 \mathrm{mM} \mathrm{H}_{2} \mathrm{O}_{2}$. Absorbance was measured at $470 \mathrm{~nm}$. The POD activity is expressed as $\mathrm{U} / \mathrm{min}$ protein 


\section{TBARS activity}

Lipid peroxidation (TBARS) activity was performed in tissue homogenate according to Ohkawa et al. (1979). The samples were mixed with phosphate buffer $(0.1 \mathrm{M}$; $\mathrm{pH}$ 7.4) in 1:4 ratio followed by incubation at $37^{\circ} \mathrm{C}$ in a shaking water bath for 1 hour. Reaction mixture was prepared by adding $10 \%$ trichloroacetic acid and working reagent TBA ( $5 \%$ acetic acid and $20 \%$ sodium hydroxide) with sample solution. All the reaction mixtures were placed in a boiling water bath for $20 \mathrm{~min}$ followed by ice bath treatment for $10 \mathrm{~min}$ and centrifuged at $10,000 \times \mathrm{g}$ for $10 \mathrm{~min}$. The supernatant was used to measure absorbance at $532 \mathrm{~nm}$ in a clear 96-well microplate using microtitre plate reader against a reagent blank. The results were expressed as $\mathrm{nM} / \mathrm{min} / \mathrm{mg}$ tissue protein.

$\mathrm{H}_{2} \mathrm{O}_{2}$ activity

The $\mathrm{H}_{2} \mathrm{O}_{2}$ level in tissue homogenate was measured following Pick and Keisari (1981). Reaction mixture containing $100 \mu \mathrm{L}$ of tissue homogenate, $100 \mu \mathrm{L}$ of $0.28 \mathrm{nM}$ phenol red, $500 \mu \mathrm{L}$ of $0.05 \mathrm{M}$ potassium phosphate buffer ( $\mathrm{pH} 7.0$ ), $250 \mu \mathrm{L}$ of $5.5 \mathrm{nM}$ dextrose and 8 units of horse radish peroxidase was incubated at $37^{\circ} \mathrm{C}$ for $40 \mathrm{~min}$. After this incubation step, $100 \mu \mathrm{L}$ of $10 \mathrm{~N} \mathrm{NaOH}$ was mixed in tubes to stop reaction, followed by centrifugation at $800 \mathrm{~g}$ for 15 minutes. Supernatant was collected and absorbance was taken at $610 \mathrm{~nm} . \mathrm{H}_{2} \mathrm{O}_{2}$ activity was expressed in $\mathrm{nM} / \mathrm{min} / \mathrm{mg}$ tissue.

\section{GSH activity}

Tissue homogenate $(1 \mathrm{~mL})$ and sulfosalicylic acid $(1 \mathrm{~mL})$ were mixed, kept at $4{ }^{\circ} \mathrm{C}$ for 1 hour and centrifuged at $1200 \times \mathrm{g}$ for $20 \mathrm{~min}$ at $4{ }^{\circ} \mathrm{C}$. The final volume of 3 $\mathrm{mL}$ reaction mixture contained $2.7 \mathrm{~mL}$ phosphate buffer (0.1 M; pH 7.4), $0.1 \mathrm{~mL}$ filtered solution and $0.2 \mathrm{~mL}$ DTNB $(100 \mathrm{mM})$ followed by measurement of absorbance at $412 \mathrm{~nm}$ (Ellman, 1959). The GSH activity is expressed as $\mathrm{mM} / \mathrm{g}$ protein

\section{NO activity}

$\mathrm{NO}-2 / \mathrm{NO}-3$ levels were estimated colorimetrically in tissue samples, following Berkels et al. (2004). The Griess reaction was used to determine nitrite and nitrate levels thereby allowing chemical reaction between sulfanilamide and $N$-1-naphthylethylenediamine dihydrochloride under acidic condition. Resulting bright reddish-purple colored azo-compound was quantified at $540 \mathrm{~nm}$. By using standard curve of sodium nitrite, NO concentration was calculated. Nitrite activity was presented as $\mu \mathrm{Mol} / \mathrm{mL}$.

\section{Histopathological analysis}

For histopathological analysis tissues were excised from slaughtered animals and were immediately washed with saline and fixed in a fixative (absolute ethanol $60 \%$, formaldehyde $30 \%$ and glacial acetic acid $10 \%$ ) and embedded in paraffin wax after xylene washing. Sections of $5 \mu \mathrm{m}$ thickness were cut by microtome and allowed to stain with hematoxylin-eosin. Sections were examined under light microscope (DIALUX $20 \mathrm{~EB}$ ) at 10X and 40X. Slides of all groups were photographed with examination of minimum 14 fields of each section.

\section{Statistical analysis}

The results were evaluated by one-way ANOVA followed by Dunnett's multiple-comparison test by using GraphPad Prism 5.0 software. The results were stated as mean \pm SEM (standard error mean). Differences were reflected to be statistically significant at $\mathrm{p}<0.05$.

\section{RESULTS}

\section{Dose tolerance test}

No mortality was recorded in the experimental animals at any dose from $100 \mathrm{mg} / \mathrm{kg} \mathrm{BW}$ upto maximum of $1000 \mathrm{mg} / \mathrm{kg}$ BW. Consequently, $400 \mathrm{mg} / \mathrm{kg} \mathrm{BW}$ of the maximum dose was considered as optimal dose for the antidiabetic study.

\section{Hypoglycemic activity of $H$. nepalensis extracts and lupeol in diabetic rats}

The diabetic control group showed glucose range of $399 \pm 9.3$ to $508 \pm 3.6 \mathrm{mg} / \mathrm{dL}$ during the 15 days experiment (Table I). The glucose level in glibenclamide group was significantly $(\mathrm{p}<0.005)$ lowered to $80.2 \%$ on 15 th day when compared to day 0 (Figure 1). The crude extract of H. nepalensis produced $55.1 \%$ reduction in the blood glucose level of diabetic rats while among the fractions, HNN resulted in $70.0 \%$ decrease in the level of blood glucose (Figure 1). Glucose level was lowered from $340 \pm 4.1 \mathrm{mg} / \mathrm{dL}$ 
on day 0 to $105 \pm 3.2 \mathrm{mg} / \mathrm{dL}$ on day 15 in lupeol group (Table I; Figure 1). Whereas HNE and HNA also showed a reduction in elevated glucose level upto maximum of $32.0 \%$ and $34.6 \%$ respectively.

TABLE I - Effect of H. nepalensis extracts and lupeol on blood glucose level (mg/dL) in alloxan induced diabetic rats

\begin{tabular}{|c|c|c|c|c|c|c|c|c|c|c|}
\hline Groups & $\mathbf{0 ~ h}$ & $0.5 \mathrm{~h}$ & $1 \mathrm{~h}$ & $2 \mathrm{~h}$ & $4 \mathrm{~h}$ & $3^{\text {rd day }}$ & $5^{\text {th }}$ day & $9^{\text {th }}$ day & $12^{\text {th }}$ day & $15^{\text {th }}$ day \\
\hline $\mathrm{DC}$ & $399 \pm 9.3$ & $505 \pm 4.5$ & $508 \pm 3.6$ & $496 \pm 3.8$ & $490 \pm 4.0$ & $495 \pm 2.9$ & $490 \pm 4.3$ & $492 \pm 3.1$ & $493 \pm 2.0$ & $499 \pm 3.8$ \\
\hline $\mathrm{NC}$ & $98 \pm 3.9^{*}$ & $91 \pm 3.3^{*}$ & $97 \pm 6.4^{*}$ & $101 \pm 3.1^{* *}$ & $93 \pm 5.5^{*}$ & $92 \pm 2.8^{* *}$ & $95 \pm 3.3^{*}$ & $92 \pm 4.1^{*}$ & $94 \pm 1.8^{* *}$ & $96 \pm 4.0^{* *}$ \\
\hline $\mathrm{DC}+\mathrm{HNC}$ & $401 \pm 11.7^{\mathrm{NS}}$ & $425 \pm 13.2^{\mathrm{NS}}$ & $399 \pm 12.5^{\mathrm{NS}}$ & $289 \pm 9.1^{\mathrm{NS}}$ & $248 \pm 17.9^{\mathrm{NS}}$ & $250 \pm 4.7^{*}$ & $265 \pm 5.5^{*}$ & $255 \pm 3.3^{* *}$ & $225 \pm 4.2^{*}$ & $224 \pm 4.9^{*}$ \\
\hline $\mathrm{DC}+\mathrm{HNN}$ & $400 \pm 6.19^{*}$ & $254 \pm 4.7^{* *}$ & $201 \pm 2.4^{* *}$ & $179 \pm 4.0^{* *}$ & $159 \pm 4.3^{* *}$ & $155 \pm 2.5^{* *}$ & $149 \pm 3.8^{* *}$ & $154 \pm 2.2^{*}$ & $148 \pm 2.2^{* *}$ & $150 \pm 2.4^{*}$ \\
\hline $\mathrm{DC}+\mathrm{HNE}$ & $394 \pm 5.3^{\mathrm{NS}}$ & $362 \pm 10.9^{\mathrm{NS}}$ & $345 \pm 6.4^{*}$ & $333 \pm 9.9^{\mathrm{NS}}$ & $343 \pm 6.1^{*}$ & $348 \pm 4.3^{*}$ & $340 \pm 4.9^{*}$ & $342 \pm 4.8^{*}$ & $335 \pm 3.3^{*}$ & $343 \pm 3.9^{* *}$ \\
\hline $\mathrm{DC}+\mathrm{HNA}$ & $407 \pm 4.2^{\mathrm{NS}}$ & $455 \pm 28.6^{\mathrm{NS}}$ & $402 \pm 6.7^{*}$ & $356 \pm 9.1^{\mathrm{NS}}$ & $365 \pm 6.5^{*}$ & $358 \pm 5.6^{*}$ & $339 \pm 3.7^{* *}$ & $322 \pm 3.6^{* *}$ & $346 \pm 4.1^{*}$ & $365 \pm 4.7^{*}$ \\
\hline
\end{tabular}

Where "NC" is normal control, "DC" is diabetic control, "HNC" is H. nepalensis crude extract, "HNN" is H. nepalensis n-hexane fraction, "HNE" is H. nepalensis ethyl acetate fraction, "HNA" is H. nepalensis aqueous fraction and "Gilb" is glibenclamide served as positive control. Values are $* \mathrm{p}<0.05$ and $* * \mathrm{p}<0.01$ statistically significant as compared to diabetic control group expressed as means \pm SEM whereas ${ }^{\mathrm{NS}}$ represents non-significant.

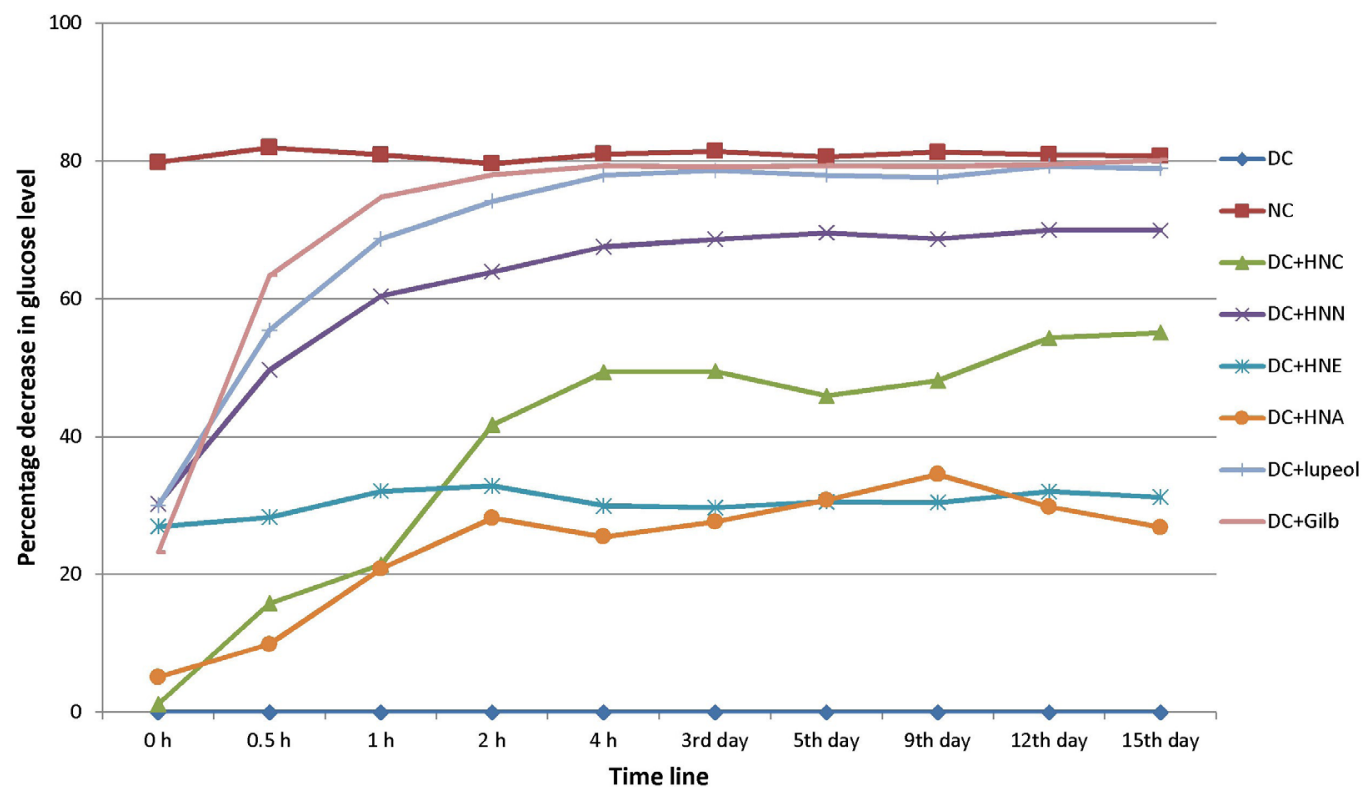

FIGURE 1 - Change (percent) in blood glucose level of alloxan induced diabetic rats on different timeline. Values are significant at $* \mathrm{p}<0.05$ as compared to diabetic control group expressed as means. Where "NC" is normal control, "DC" is diabetic control, "HNC" is $H$. nepalensis crude extract, "HNN" is H. nepalensis n-hexane fraction, "HNE" is H. nepalensis ethyl acetate fraction, "HNA" is $H$. nepalensis aqueous fraction and "Gilb" is glibenclamide served as positive control. 


\section{Effects of HNC, HNN, HNE, HNA and lupeol on pancreatic activity in blood serum}

The effects of glibenclamide, lupeol, H. nepalensis crude extract and fractions on various pancreatic enzymes of diabetic rats are presented in the Figure 2. Normalization of insulin level is represented in Figure 2 a with subsequent treatment of glibenclamide, extracts and lupeol on 15 days. Most significant $(\mathrm{p}<0.05)$ results were depicted by HNN and lupeol treatment. Plasma insulin level decreased in diabetic control, which shows negative impact of decrease in activity as compared to amylase and lipase. Increase in plasma insulin level was increasing in rats treated with HNN and lupeol. Elevated amylase and lipase level in diabetic rats also decreased by the extracts and fractions of $H$. nepalensis as compared to diabetic control (Figure 2b). HNN showed moderate while lupeol exhibited significant $(\mathrm{p}<$ 0.05 ) reduction in glucose level compared to the normal control and glibenclamide group.
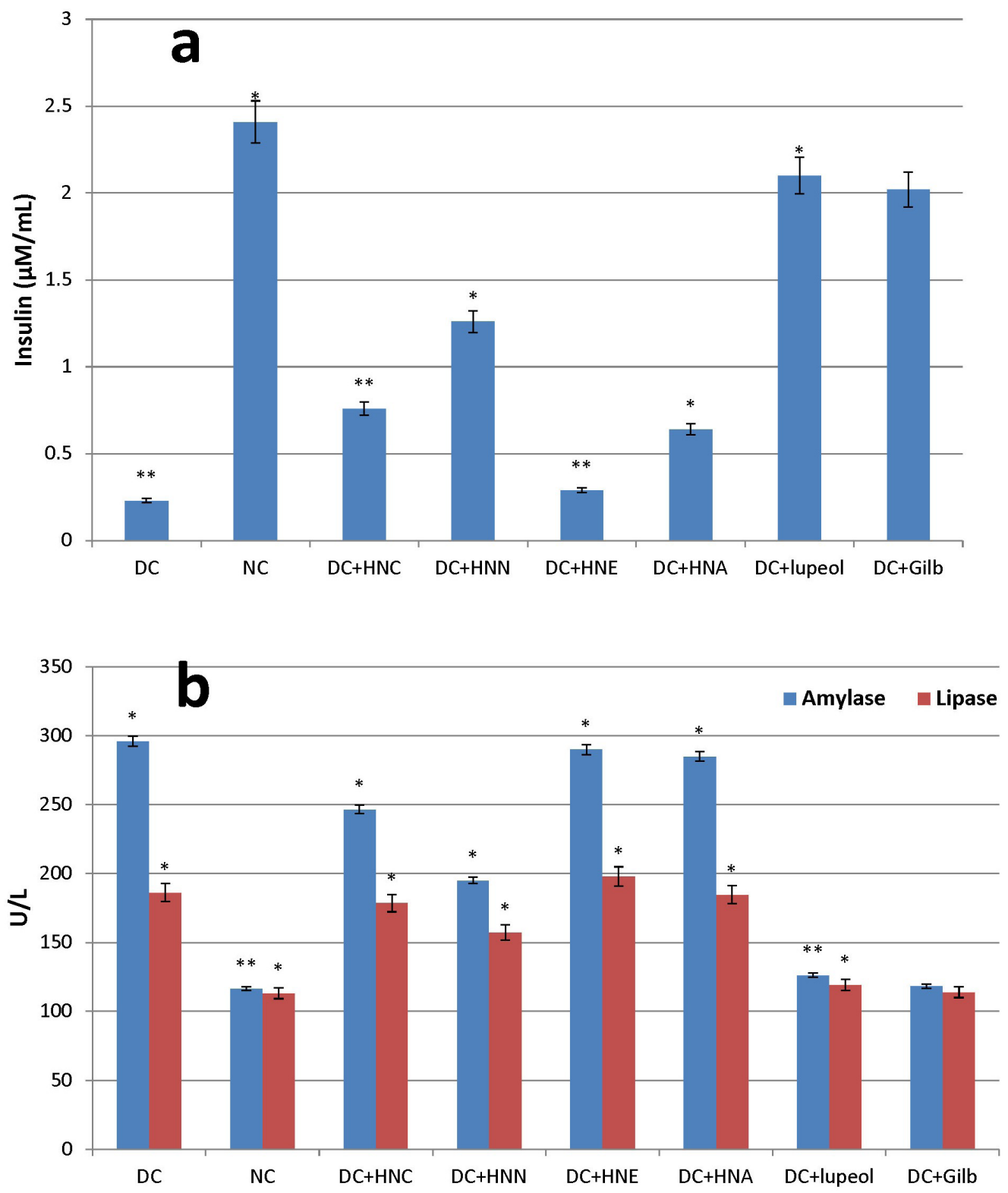

FIGURE 2 - (a) insulin level (b) amylase and lipase level after 15 days of treatment. Values are *p $<0.05$ and **p $<0.01$ statistically significant as compared to positve control group expressed as means. Where "NC" is normal control, "DC" is diabetic control, "HNC" is H. nepalensis crude extract, "HNN" is H. nepalensis n-hexane fraction, "HNE" is H. nepalensis ethyl acetate fraction, "HNA" is H. nepalensis aqueous fraction and "Gilb" is glibenclamide served as positive control. 


\section{Effects of HNC, HNN, HNE, HNA and lupeol on liver, kidney and heart biomarkers in blood serum}

H. nepalensis crude extract and fractions were tested to determine levels of different biomarkers (total protein, total bilirubin, ALT, AST, BUN, creatinine) altered due to induction of alloxan. A significant change in levels of these biomarkers was observed in diabetic rats in comparison to that of the normal control rats (Table II). In case of liver, elevated level of ALT, AST, total bilirubin and total protein level of diabetic rats were decreased by the effect of extract and fractions in comparison to diabetic control (Table II). In particular,
HNN and lupeol showed a significant $(\mathrm{p}<0.05)$ decrease of $35.1 \%$ and $60.4 \%$ in ALT level, respectively. Similar pattern for decreased level of AST (HNN: 50.1\% and lupeol: 63.7\%), total bilirubin (HNN: 45.8\% and lupeol: 29.2\%) and total protein level (HNN: $39.0 \%$ and lupeol: $25.6 \%$ ) was observed as compared to diabetic control. High biochemical parameters of kidney (creatinine and BUN) were decreased on treatment with different extracts and lupeol. Promising decrease in levels was shown by HNN and lupeol in both tests as compared to other groups (Table II). Figure 3 represents the percentage of the all biochemical parameters calculated from diabetic control group.

TABLE II - Effects of $H$. nepalensis extracts and lupeol on liver, kidney and heart biomarkers in alloxan induced diabetic rats

\begin{tabular}{|c|c|c|c|c|c|c|c|c|c|}
\hline Organ & $\begin{array}{l}\text { Biomarker } \\
\text { (Unit) }\end{array}$ & NC & DC & $\mathrm{DC}+\mathrm{HNC}$ & $\mathrm{DC}+\mathrm{HNN}$ & DC+HNE & DC+HNA & DC+lupeol & DC + Gilb \\
\hline & ALT (U/L) & $22.1 \pm 2.4^{*}$ & $57.3 \pm 2.1^{*}$ & $35.2 \pm 8.8^{\mathrm{NS}}$ & $37.2 \pm 1.6^{* *}$ & $31.2 \pm 7.8^{\mathrm{NS}}$ & $30.5 \pm 3.5^{*}$ & $22.7 \pm 0.9^{* *}$ & $23.6 \pm 1.5$ \\
\hline & AST (U/L) & $22.5 \pm 2.9^{*}$ & $73.6 \pm 2.1^{*}$ & $42.6 \pm 3.6^{*}$ & $36.7 \pm 1.6^{* *}$ & $38.9 \pm 3.1^{*}$ & $34.4 \pm 2.1^{*}$ & $26.7 \pm 1.0^{* * *}$ & $24.2 \pm 1.1$ \\
\hline
\end{tabular}

Liver Total

bilirubin $\quad 0.35 \pm 0.05^{*} 1.20 \pm 0.04^{*} \quad 0.71 \pm 0.06^{*} \quad 0.65 \pm 0.02^{* *} 0.65 \pm 0.07^{*} 0.61 \pm 0.05^{*} \quad 0.85 \pm 0.02^{* *} 0.38 \pm 0.01$

$(\mathrm{mg} / \mathrm{dL})$

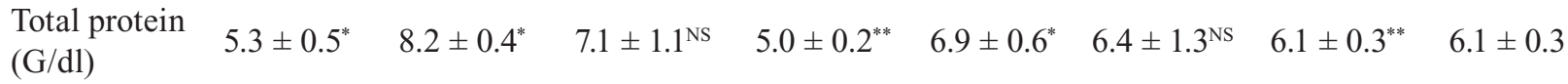

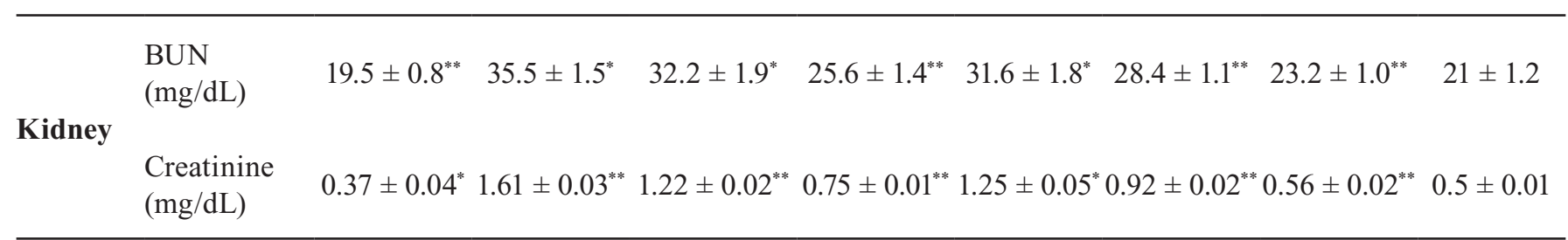

Where "NC" is normal control, "DC" is diabetic control, "HNC" is H. nepalensis crude extract, "HNN" is H. nepalensis n-hexane fraction, "HNE" is H. nepalensis ethyl acetate fraction, "HNA" is H. nepalensis aqueous fraction and "Gilb" is glibenclamide served as positive control. Values are * $\mathrm{p}<0.05$ and $* * \mathrm{p}<0.01$ statistically significant as compared to positive control group expressed as means \pm SEM whereas ${ }^{\mathrm{NS}}$ represents non-significant. 


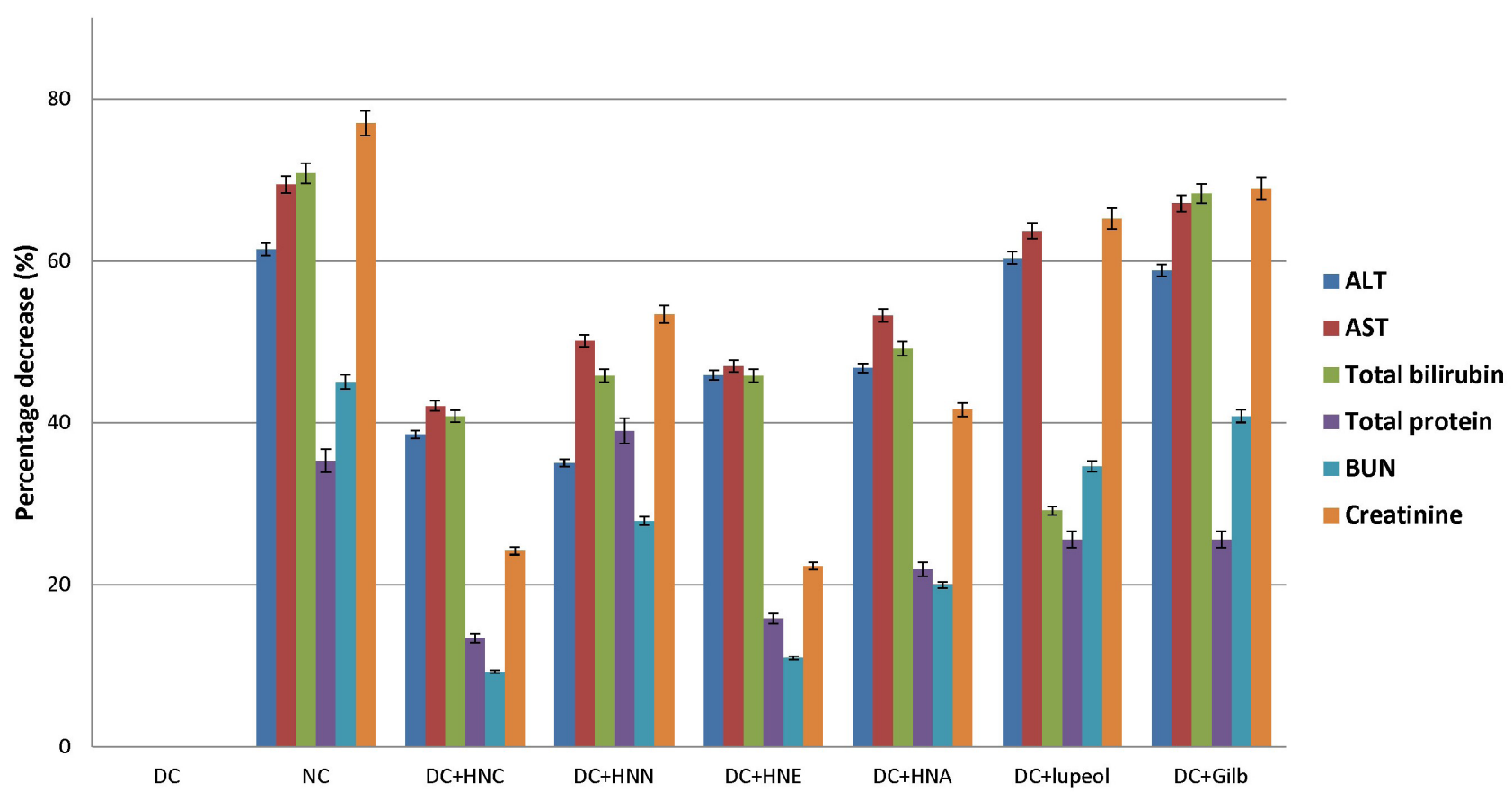

FIGURE 3 - Percentages of biochemical parameters after 15 days of treatment. Where "NC" is normal control, "DC" is diabetic control, "HNC" is H. nepalensis crude extract, "HNN" is H. nepalensis n-hexane fraction, "HNE" is H. nepalensis ethyl acetate fraction, "HNA" is H. nepalensis aqueous fraction and "Gilb" is glibenclamide served as positive control.

\section{Effect of $H$. nepalensis and lupeol on tissue protein, $\mathrm{H}_{2} \mathrm{O}_{2}$, TBARS and nitrite contents}

Alloxan induction significantly increased the tissue protein, $\mathrm{H}_{2} \mathrm{O}_{2}$, TBARS and nitrite contents in diabetic control group (Table III). H. nepalensis crude extract, its fractions and lupeol exhibited significant $(p<0.05)$ reduction against elevated level of above mentioned parameters at various potential. TBARS level was restored to normal level of $30.4 \mathrm{nM} / \mathrm{min} / \mathrm{mg}$ in pancreas, $35.1 \mathrm{nM} / \mathrm{min} / \mathrm{mg}$ in liver and $29.9 \mathrm{nM} /$ $\mathrm{min} / \mathrm{mg}$ in kidneys, (diabetic controls contained upto $60.5 \mathrm{nM} / \mathrm{min} / \mathrm{mg}$ tissue). When diabetic rats were treated with HNN, decreased in TBARS activity of kidney (51.7\%), liver (27\%) and pancreas (37.4\%) was recorded. Lupeol significantly reduced TBARS level: 41.1\% (liver), 46.6\% (kidney) and 46.5\% (pancreas). Hydrogen peroxide activity was also reduced in liver (28.3\%), kidney (19.5\%) and pancreas (40.2\%) of HNN group rats. Lupeol showed decrease in activity of $\mathrm{H}_{2} \mathrm{O}_{2}$ for liver (29.6\%), kidney (21.9\%) and pancreas (43.8\%) as compared to diabetic control. Decrease in in vitro nitrite content of organ especially liver and pancreas as compared to diabetic control was observed to the level of $25.2 \%$ and $20.2 \%$ for respective organs, when treated with HNN. Lupeol showed decrease of $29.4 \%$ for liver and $16.6 \%$ for pancreas as compared to diabetic control. $H$. nepalensis and lupeol treatment notably restored the contents which were prominently significant $(p<0.05)$ when compared to that of the diabetic control group. 
TABLE III - Effects of $H$. nepalensis extracts and lupeol on pancreas, liver, kidney and heart biomarkers in alloxan induced diabetic rats

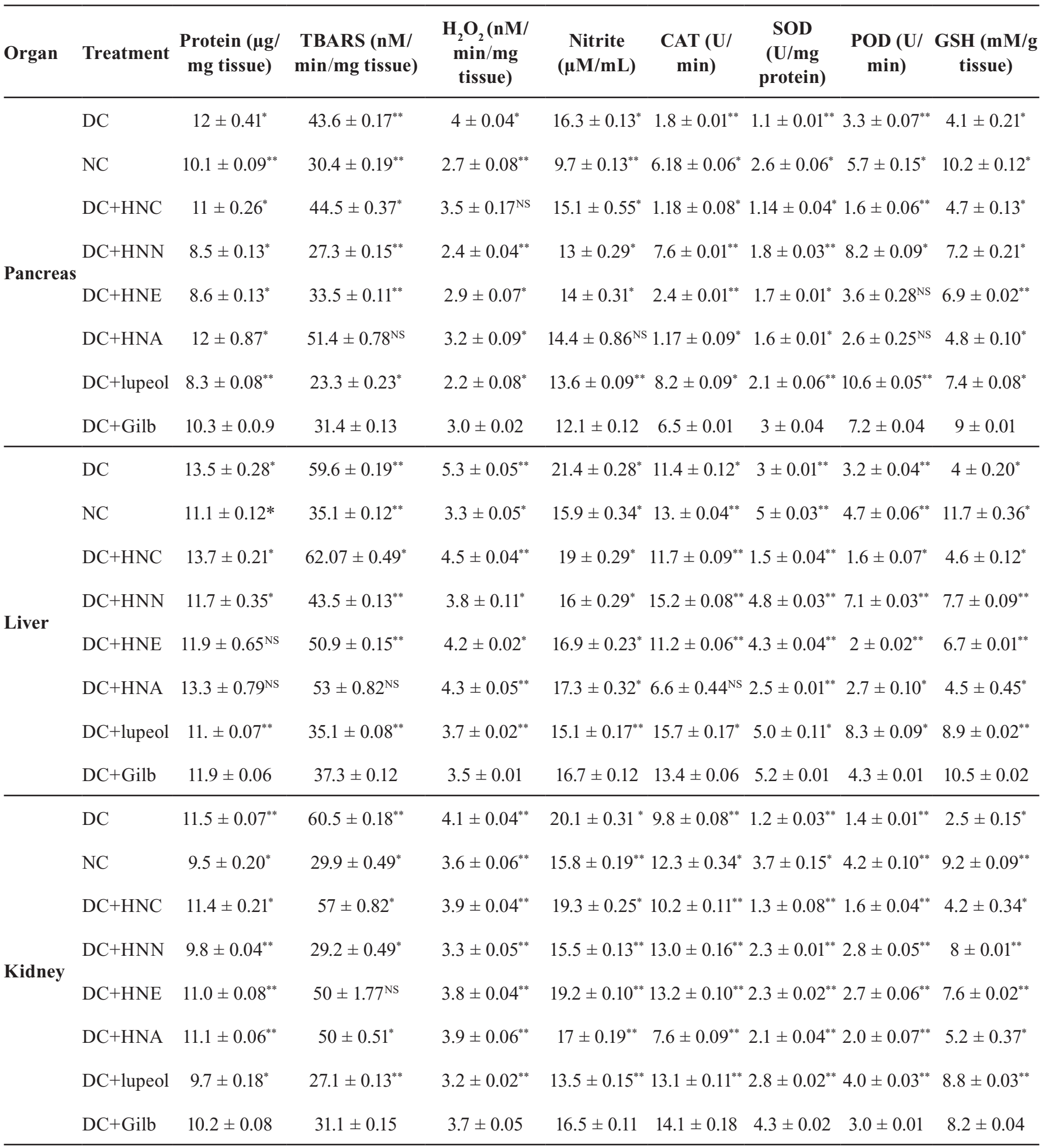

Where "NC" is normal control, "DC" is diabetic control, "HNC" is H. nepalensis crude extract, "HNN" is H. nepalensis n-hexane fraction, "HNE" is $H$. nepalensis ethyl acetate fraction, "HNA" is H. nepalensis aqueous fraction and "Gilb" is glibenclamide served as positive control. Values are $* \mathrm{p}<0.05$ and $* * \mathrm{p}<0.01$ statistically significant as compared to positive control group expressed as means $\pm \mathrm{SEM}$ whereas ${ }^{\mathrm{NS}}$ represents non-significant. 


\section{Estimation of antioxidant level treated with $H$. nepalensis and lupeol}

Diabetes mellitus induced by alloxan significantly reduced antioxidant enzymes (CAT, POD, SOD and GSH) level as presented in Table III. The results depicted the positive effect of $H$. nepalensis extract and fractions on these antioxidant enzymes. The treatment of these extracts restored the level of enzyme to normal values (Table III). Glibenclamide improved CAT activity. The treatment of $\mathrm{HNN}$ and lupeol increased the activity upto $78 \%$ as compared to diabetic control. In SOD assay, the increase in enzyme activity was recorded upto $47.2 \%$. SOD activity was decreased in diabetic control liver (39.9\%) and pancreas (57.1\%) with significant increase in activity of $36.9 \%$ in liver and $40 \%$ in pancreas, in HNN treated group. Similarly, SOD and POD activity was decreased in liver, kidney and pancreas in alloxan treated groups. In glibenclamide, $\mathrm{HNN}$ and lupeol groups, the SOD and POD activitied were significantly $(\mathrm{p}<0.05)$ increased (Table III). The decrease in GSH activity in alloxan treated experimental condition was significantly improved in liver and pancreas (42.3\%) in HNN and lupeol groups. Overall, results showed that CAT, POD, SOD and GSH levels were increased significantly $(\mathrm{p}<0.05)$ by $H$. nepalensis and lupeol treatment in diabetic rats.

\section{Histopathological analysis}

Effect of H. nepalensis on liver, kidney and pancreas histology in different groups is illustrated in Figures 4-6. Pancreatic histological examination (Figure 4) of normal control showed normal islet of Langerhans (IL) with constant number of beta cells while diabetic control group showed destructed IL cells with scarcity of beta cells and large necrosis (N). HNC, HNE and HNA groups displayed nearly identical physiology as compared to diabetic control. In contrast, HNN and lupeol groups showed normal tissue physiology of pancreatic tissues with constant number of beta cells. Histological pattern of diabetic liver (Figure 5) showed sinusoidal dilution (SD) with scattered inflammation (SI) along with non-demarcated hepatocyte (HCNDM) and nuclear joining (NJ) characteristics of disease condition. The groups of normal rats, HNN, lupeol and glibenclamide showed nearly identical results of intact central venule (CV), hepatocytes (HC) and sinusoidal space (SS). Physiology of normal kidney (Figure 6) showed average bowmen capsule (BC) size whereas diabetic rats showed increased BC size with couple of interstitial blood vessels (IBV) along with fatty density (FD). The HNC, HNE and HNA grouped showed same results as diabetic control group. But HNN, lupeol and glibenclamide groups exhibited improvement in physiology of kidney tissue comparable with normal control. Alloxan-induced diabetic rats produced sinusoidal dilation and necrosis which were cured by the extract treatment. This could have resulted from the capability of the extract to enhance antioxidant activities.

\section{DISCUSSION}

Oxidative stress is thought to be the major cause in development and pathogenesis related to complications of DM. Liver functions tests are regularly prescribed by physicians to monitor the progression of known diseases (Atasoy et al., 2007). Hepatoxicity is accentuated cause of DM. Elevated ALT, AST, total protein and total bilirubin in alloxan treated diabetic control coincide with previous observation that diabetic patients usually tend to have high transaminases activity (Ahn et al., 2014). In the current study, substantial decrease in activity of liver function tests such as AST, ALT, total bilirubin and total protein after treatment with $\mathrm{HNN}$ and lupeol mainly attributed to defence of intracellular enzyme leakage and cellular stability. This has been reported for other ethnopharmacologically important antioxidant plants (Thabrew, Joice, Rajatissa, 1987).

Reactive oxygen species associated with oxidative destruction are counteracted by different defense mechanisms such as SOD, CAT, POD and GSH (Tiwari et al., 2013). In present study, the treatment of alloxan triggered reduction in activity of SOD, POD, CAT and $\mathrm{GSH}$, and increase in TBARS levels led to decrease in antioxidant protection potential (Tiwari et al., 2013). However, HNN and lupeol treatment produced promising increase in activity of SOD, POD, CAT and GSH in liver and pancreas. CAT, SOD and those compound having hydroxyl radical scavenging property antagonist to alloxan; provide the indication that alloxan illicit its action by superoxide anion and hydroxyl radical (Grankvist et al., 1981). HNN and lupeol produced effect by scavenging reactive oxygen species, either due to existence of diverse antioxidant compounds or through increasing biosynthesis of antioxidant compounds (Santiago, Mayor, 2014). 

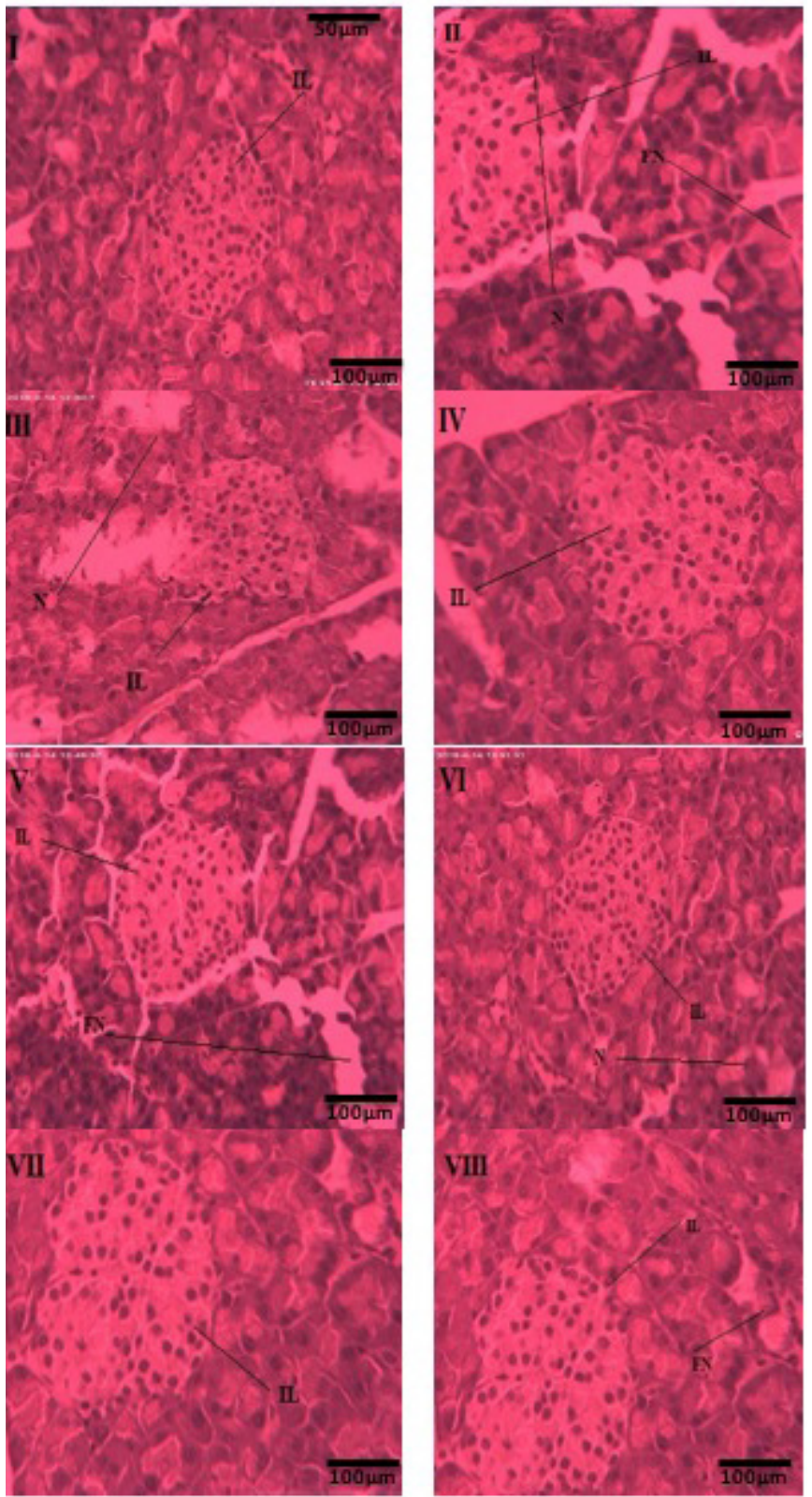

FIGURE 4 - Histology of the pancreas. (I) normal control, (II) diabetic control, (III) HNC, (IV) HNN, (V) HNE, (VI) HNA, (VII) lupeol and (VIII) glibenclamide. Samples were magnified at $40 \mathrm{X}$ and "IL" is Islet of Langerhans, "N" is necrosis and "FN" is focal necrosis.
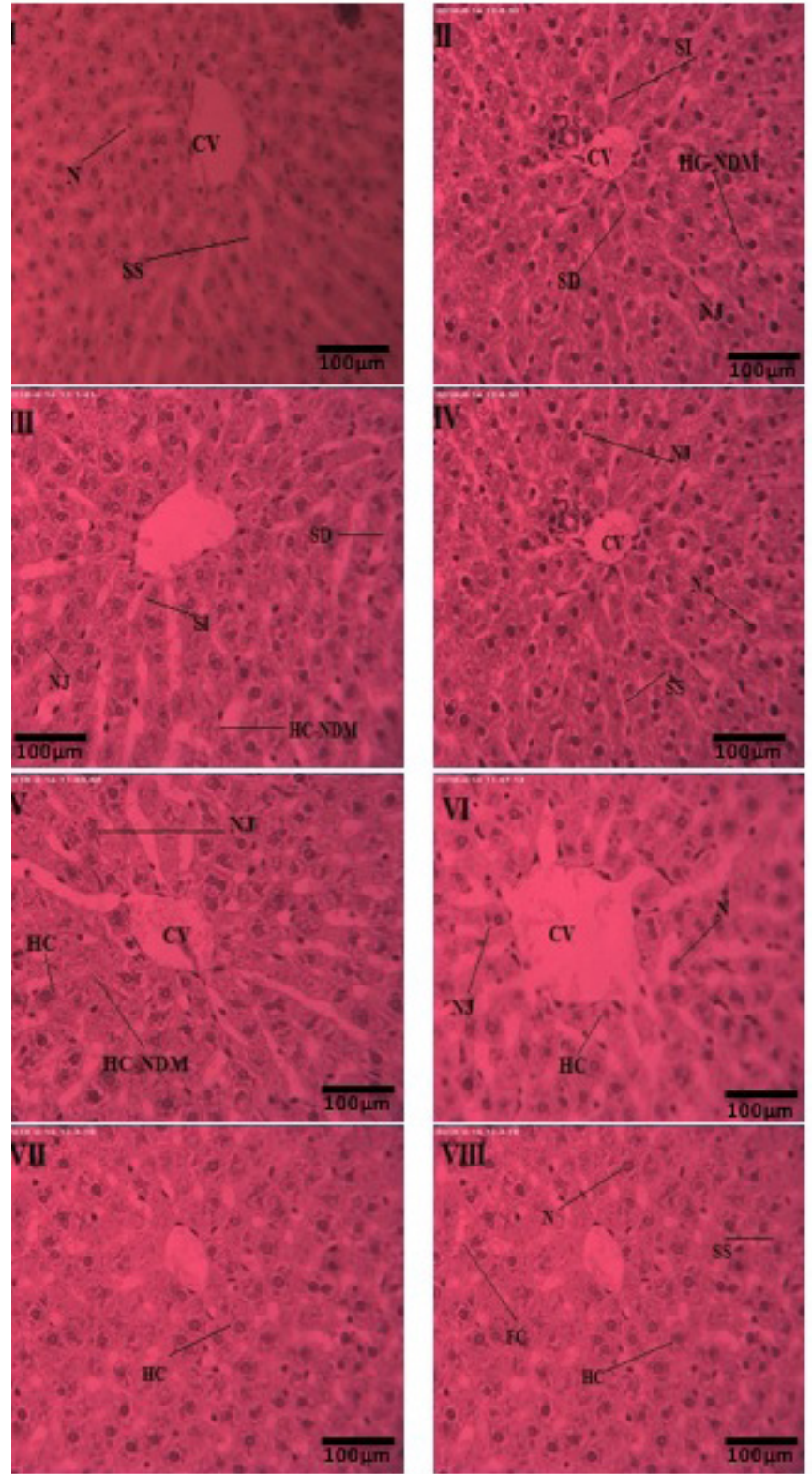

FIGURE 5 - Histology of the liver. (I) normal control, (II) diabetic control, (III) HNC, (IV) HNN, (V) HNE, (VI) HNA, (VII) lupeol and (VIII) glibenclamide. Samples were magnified at $40 \mathrm{X}$ and "CV" is central venule $(\mathrm{CV})$, "HC" hepatocytes, "SS" sinusoidal space, "SD" is sinusoidal dilution, "SI" is scattered inflammation, "HC-NDM" is non-demarcated hepatocyte, "NJ" is nuclear joining and "N" is necrosis. 

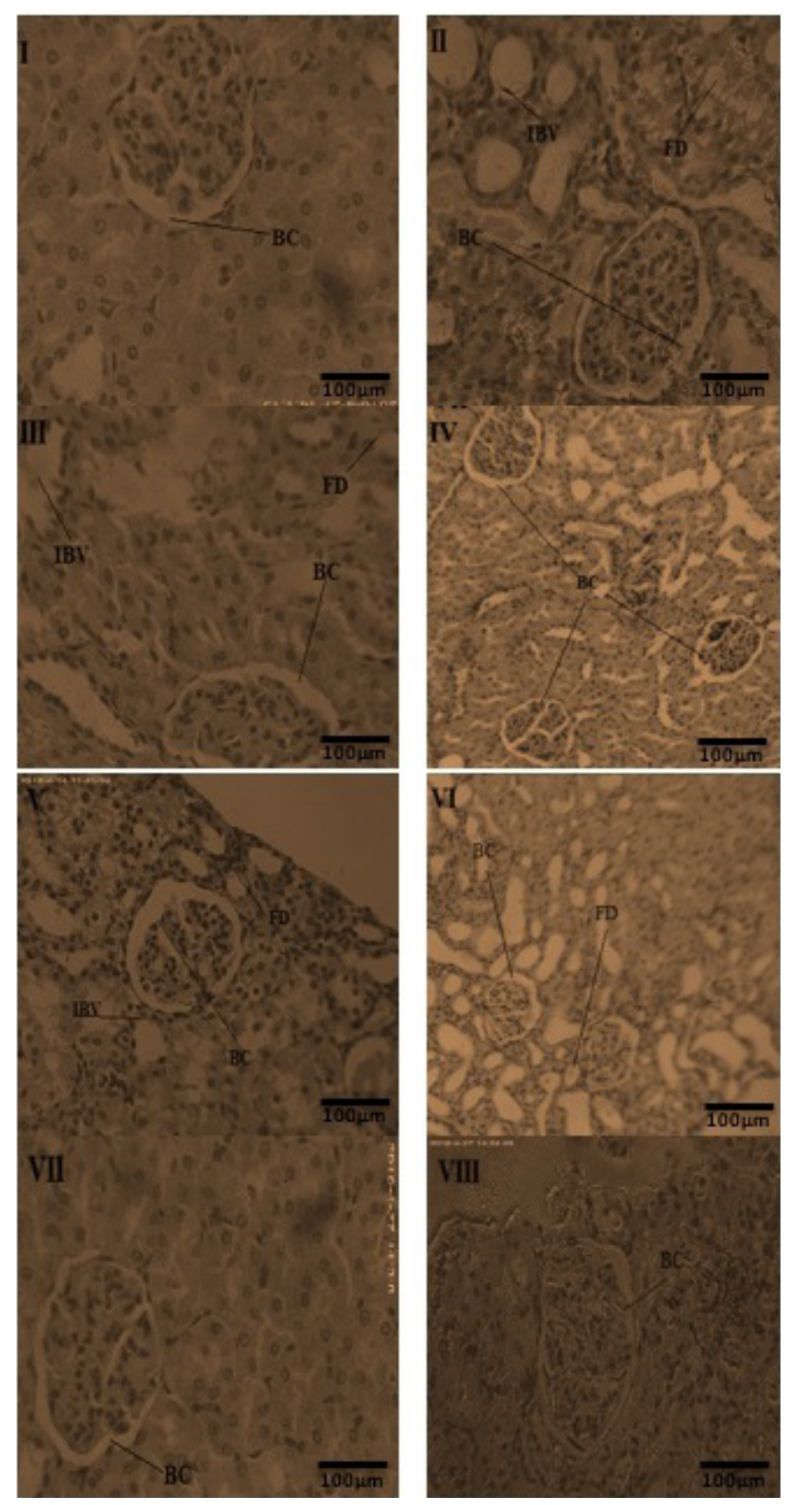

FIGURE 6 - Histology of the kidney. (I) normal control, (II) diabetic control, (III) HNC, (IV) HNN, (V) HNE, (VI) HNA, (VII) lupeol and (VIII) glibenclamide. Samples were magnified at $40 \mathrm{X}$ and "BC" is bowmen capsule, "IBV" is interstitial blood vessels and "FD" is fatty density.
Lipid peroxidation causes oxidative stress that is mainly attributed to the chronic stage of DM (Elangovan et al., 2000). In our study, TBARS, $\mathrm{H}_{2} \mathrm{O}_{2}$ and nitrite level increased in alloxan treated experimental control, due to the fact that alloxan damages $\beta$-cells of pancreas by producing reactive free radical species. This results in membrane damage due to glycation and peroxidation of protein and lipid, respectively (Baynes, 1991), and leads to increase in blood glucose level. Treatment with HNN and lupeol causes decrease in level of TBARS, $\mathrm{H}_{2} \mathrm{O}_{2}$ and nitrite. This observation may be due to the fact that destructive effect of $\mathrm{O} 2 \bullet$ and $\mathrm{OH} \bullet$ radical is counteracted by the component of antioxidant defense system like SOD, CAT and GSH and they help to neutralize or eliminate the effect of free radical oxygen species. Strong evidences have shown the role of reactive oxygen species (ROS) in DM and many experiments have shown the destruction of tissue in DM (Kakkar et al., 1995). Under normal circumstances, antioxidant system of body protects against the free radical species generated during chronic diabetic stage in vivo.

In present study, amplified nitrite level clearly depicted the role of nitric oxide (NO) free radical pool generated in pancreas of diabetic control. NO produced by $\beta$-cells of pancreas, in treatment with alloxan, has been associated in the advancement of diabetes (Sentman, Josson, Marklund, 1999). The role of NO, ROS and peroxynitrite-derived species (NO+ superoxide anions) in diabetes has been shown in streptozotocin-induced diabetic rats with increased activity of NO in kidney (Stadler et al., 2003).

Lupeol activity at the dose of merely $3 \mathrm{mg} /$ $\mathrm{kg} \mathrm{BW}$ was noted to be greater than glibenclamide $(5 \mathrm{mg} / \mathrm{kg}$ bw) in provoking hypoglycaemic response in alloxan induced diabetic control. Both HNN and lupeol increased insulin level to $452.5 \%$ and $820.6 \%$, respectively as compared to diabetic control. Lupeol group showed 3.95\% higher insulin concentration than glibenclamide treated group. Some observations supported the role of lupeol as blocker of $\alpha$-amylase activity, and therefore conclude that inhibition of $\alpha$-amylase is feature of the triterpenoid structure (Ali, Houghton, Soumyanath, 2006). We previously reported the highest flavonoid and phenolic contents in HNC and HNE extracts, catechin and caffeic acid in HNA and HNE respectively, and rutin and chlorogenic acid in crude extracts of $H$. nepalensis (Inayatullah et al., 2012). Flavonoids have anti-hyperglycemic activity (Cho et al., 2010), act as inhibitors of DPP-4 
(Parmar et al., 2012), and help improve the glycemic status in animal models.

To sum up, the data reflected in alloxan treated rats exhibited following responses: (1) HNN and lupeol significantly reduced plasma glucose level, (2) HNN or lupeol treatment increased the oral glucose tolerance, (3) a protective effect was seen against diabetes related liver, pancreas and kidney injuries after treatment with both HNN and lupeol, and (4) most important and promising results of HNN and lupeol was enhanced insulin levels after treatment in dose dependent and time dependent way. We show that $H$. nepalensis can ameliorate the symptoms of diabetes and regulate the glucose metabolism. Its antioxidative properties protect the liver, kidney and pancreatic tissue against diabetogenic injury. Although $H$. nepalensis showed significant anti-hyperglycaemic activity, it also has ability to enhance de novo insulin production. This plant could be future potential therapeutic medicinal plant against diabetes and its related disease.

\section{COMPETING INTERESTS}

Authors declare no conflict of interests regarding the publication of this paper.

\section{AUTHOR'S CONTRIBUTIONS}

$\mathrm{HI}$ and WJH conducted all the assays and experimental work. BM conceived the study design and supervised the study. LJ contributed in study design and isolated lupeol previously. HI and WJH drafted the manuscript and all authors proof read the final version.

\section{ACKNOWLEDGMENT}

Authors acknowledge the animal ethical committee for approving to wrk on rat models and the technical staff for their help and support during execution of this project. Authors greatly acknowledge the Biological Manuscripts Editing Services (BioMES) of Alpha Genomics Private Limited, Islamabad, Pakistan, for their contribution to improve scientific communication of this study.

\section{ABBREVIATIONS}

DM: Diabetes Mellitus

HNC: H. nepalensis crude extract

HNN: Hedera nepalensis n-hexane fraction
HNE: Hedera nepalensis ethyl acetate fraction

HNA: Hedera nepalensis aqueous fraction

OECD: Organization for Economic Cooperation and Development

NC: $\quad$ Normal Control, non-diabetic

DC: Diabetic Control

BW: Body weight

ELISA: Enzyme-linked immunosorbent assay

ALT: Alanine transaminases

AST: Aspartate transaminases

CAT: Catalase

SOD: Superoxide dismutase

GSH: Reduced glutathione

POD: Peroxidase

BUN: Blood urea nitrogen

TBARS: Thiobarbituric acid reactive substances

ROS: Reactive oxygen species

\section{REFERENCES}

Aebi H. Catalase in vitro. Methods Enzymol. 1984;105:121-26.

Ahn HR, Shin MH, Nam HS, Park KS, Lee YH, et al. The association between liver enzymes and risk of type 2 diabetes: the Namwon study. Diabetol Metab Syndr. 2014;6:1.

Akhtar N, Rashid A, Murad W, Bergmeier E. Diversity and use of ethno-medicinal plants in the region of Swat, North Pakistan. J Ethnobiol Ethnomed. 2013;9:25.

Ali H, Houghton P, Soumyanath A. $\alpha$-amylase inhibitory activity of some Malaysian plants used to treat diabetes; with particular reference to Phyllanthus amarus. JEthnopharmacol. 2006;107(3):449-55.

Amarapurkar D, Das H. Chronic liver disease in diabetes mellitus. Trop Gastroenterol. 2001;23:3-5.

Atasoy N, Erdogan A, Yalug I, Ozturk U, Konuk N, et al. A review of liver function tests during treatment with atypical antipsychotic drugs: a chart review study. Prog Neuropsychopharmacol Biol Psychiatry. 2007;31(6):1255-60.

Bannister JV, Calabrese L. Assays for superoxide dismutase. Methods Biochem Anal. 2006;32:279-312.

Baynes JW. Role of oxidative stress in development of complications in diabetes. Diabetes. 1991;40(4):405-12.

Begum S, AbdEIslam NM, Adnan M, Tariq A, Yasmin A, Hameed R. Ethnomedicines of highly utilized plants in the temperate Himalayan region. Afr J Tradit Complement Altern Med. 2014;11(3):132-42. 
Berkels R, Purol-Schnabel S, Roesen R. Measurement of nitric oxide by reconversion of nitrate/nitrite to NO. Nitric Oxide Prot. 2004;279:1-8.

Cho A-S, Jeon S-M, Kim M-J, Yeo J, Seo K-I, et al. Chlorogenic acid exhibits anti-obesity property and improves lipid metabolism in high-fat diet-induced-obese mice. Food Chem Toxicol. 2010;48(3):937-43.

Elangovan V, Shohami E, Gati I, Kohen R. Increased hepatic lipid soluble antioxidant capacity as compared to other organs of streptozotocin-induced diabetic rats: a cyclic voltammetry study. Free Radic Res. 2000;32(2):125-34.

Ellman GL. Tissue sulfhydryl groups. Arch Biochem Biophys. 1959;82(1):70-77.

Grankvist K, Marklund S, Täljedal I-B. Superoxide dismutase is a prophylactic against alloxan diabetes. Nature. 1981;294(5837):158-60.

Gurib-Fakim A. Medicinal plants: traditions of yesterday and drugs of tomorrow. Mol Aspects Med. 2006;27(1):1-93.

Hamayun M, Khan SA, Sohn EY, Lee I-J. Folk medicinal knowledge and conservation status of some economically valued medicinal plants of District Swat, Pakistan. Lyonia. 2006;11(2):101-13.

Inayatullah S, Irum R, Ateeq-ur-Rehman, Fayyaz Chaudhary M, Mirza B. Biological evaluation of some selected plant species of Pakistan. Pharm Biol. 2007;45(5):397-403.

Inayatullah S, Prenzler PD, Obied HK, Rehman A-u, Mirza B. Bioprospecting traditional Pakistani medicinal plants for potent antioxidants. Food Chem. 2012;132(1):222-29.

Ismail H, Mirza B. Evaluation of analgesic, anti-inflammatory, anti-depressant and anti-coagulant properties of Lactuca sativa (CV. Grand Rapids) plant tissues and cell suspension in rats. BMC Complement Altern Med. 2015;15:199.

Jafri L, Saleem S, Ullah N, Mirza B. In vitro assessment of antioxidant potential and determination of polyphenolic compounds of Hedera nepalensis K. Koch. Arab J Chem. 2014;10(Suppl 2):S3699-S3706.

Jarald E, Joshi SB, Jain DC. Diabetes vs herbal medicines. Iran J Pharm Ther. 2008;7(1):97-106.

Kakkar R, Kalra J, Mantha SV, Prasad K. Lipid peroxidation and activity of antioxidant enzymes in diabetic rats. Mol Cell Biochem. 1995;151(2):113-19.

Kanwal S, Ullah N, Haq I, Afzal I, Mirza B. Antioxidant, antitumor activities and phytochemical investigation of
Hedera nepalensis K. Koch, an important medicinal plant from Pakistan. Pak J Bot. 2011;43:85-89.

Khan RA, Khan MR, Shah NA, Sahreen S, Siddiq P. Modulation of carbon tetrachloride-induced nephrotoxicity in rats by $n$-hexane extract of Sonchus asper. Toxicol Ind Health. 2015;31(10):955-59.

Leclercq IA, Morais ADS, Schroyen B, Van Hul N, Geerts A. Insulin resistance in hepatocytes and sinusoidal liver cells: mechanisms and consequences. J Hepatol. 2007;47(1):142-56.

Marx J. Unraveling the causes of diabetes. Science. 2002;296(5566):686-9.

Nakhjavani M, Morteza A, Nargesi AA, Mostafavi E, Esteghamati A. Appearance of leptin-HSP70 correlation, in type 2 diabetes. Meta Gene. 2013;1:1-7.

OECD. Organization for Economic Co-operation and Development. OECD guideline for testing chemicals 425 . Acute oral toxicity-up and down procedure. 2001;2:12-16.

Ohkawa H, Ohishi N, Yagi K. Assay for lipid peroxides in animal tissues by thiobarbituric acid reaction. Anal Biochem. 1979;95(2):351-58.

Parmar HS, Jain P, Chauhan DS, Bhinchar MK, Munjal V, et al. DPP-IV inhibitory potential of naringin: an in silico, in vitro and in vivo study. Diabetes Res Clin Pract. 2012;97(1):105-11.

Pick E, Keisari Y. Superoxide anion and hydrogen peroxide production by chemically elicited peritoneal macrophagesinduction by multiple nonphagocytic stimuli. Cell Immunol. 1981;59(2):301-18.

Ríos JL, Francini F, Schinella GR. Natural products for the treatment of type 2 diabetes mellitus. Planta Med. 2015;81(1213):975-94.

Saleem S, Jafri L, ul Haq I, Chang LC, Calderwood D, et al. Plants Fagonia cretica L. and Hedera nepalensis K. Koch contain natural compounds with potent dipeptidyl peptidase-4 (DPP-4) inhibitory activity. J Ethnopharmacol. 2014;156:26-32.

Santiago LA, Mayor ABR. Lupeol: an antioxidant triterpene in Ficus pseudopalma Blanco (Moraceae). Asian Pac J Trop Biomed. 2014;4(2):109-18.

Sentman M-L, Jonsson LM, Marklund SL. Enhanced alloxan-induced $\beta$-cell damage and delayed recovery from hyperglycemia in mice lacking extracellular-superoxide dismutase. Free Radic Biol Med. 1999;27(7-8):790-96. 
Ethnopharmacological activity of Hedera nepalensis K. Koch extracts and lupeol against alloxan-induced type I diabetes

Stadler K, Jenei V, von Bölcsházy G, Somogyi A, Jakus J. Increased nitric oxide levels as an early sign of premature aging in diabetes. Free Radic Biol Med. 2003;35(10):1240-51.

Thabrew MI, Joice P, Rajatissa W. A comparative study of the efficacy of Pavetta indica and Osbeckia octandra in the treatment of liver dysfunction. Planta Med. 1987;53(3):239-41.

Tiwari BK, Pandey KB, Abidi A, Rizvi SI. Markers of oxidative stress during diabetes mellitus. J Biomark. 2013;2013:378790.
Xue M, ZhiYing W. The volatile constituents analysis of Scindapsus aureum and Hedera nepalensis var. sinensis and their inhibition against five fungi. Acta Hortic Sin. 2010;37(6):971-76.

Received for publication on $03^{\text {rd }}$ June 2018 Accepted for publication on $24^{\text {th }}$ September 2018 